\title{
The geography of vine and wine industry in Brazil: Territory, culture and heritage / Géographie de la vigne et du vin Brésilien : territoire, culture et patrimoine
}

\author{
Ivanira Falcade ${ }^{\mathrm{a}}$ \\ University of Caxias do Sul, Master of Biotechology and Manegeman of Vine and Wine Industry, Rua Francisco Getulio Vargas, \\ 1130, CEP 95070-560, Caxias do Sul, Brazil
}

\begin{abstract}
The Portuguese started in the sixteenth century, but the colonial system did encourage neither their growth nor the establishment of territories. The organization of regions where the grape and wine formed the economic dynamic is related to the nineteenth century colonization projects, especially Italians from 1875. These regions including the Serra Gaúcha of Rio Grande do Sul and other small areas. In the twentieth century, most of these regions have had important territorial transformations, however, viticulture elements remain in culture and regional identity. In recent years, the growing of vines expanded to other regions and also in other States. The cultivation of the vine and winemaking built a brand, both for the actors and for the regional society, whose viticultural landscape distinguishes and identifies regions, and the cultural expression of the grape and wine is present in numerous material and intangible elements. The material and the intangible cultural complex of the wine-growing regions are a diverse and dynamic heritage, more concentrated in Rio Grande do Sul, which contributes to the enhancement and preservation of cultural heritage and territorial wine in this State. The wine culture valued in the actions of patrimonialization depends on the importance that give them the actors involved.
\end{abstract}

\section{Introduction et évolution de la viticulture au Brésil}

Les Portugais ont commencé la culture de la vigne et du vin au Brésil au XVIe siècle ; en 1532, dans la capitainerie de São Vicente, actuelle São Paulo et dans les années 1550, elle a été introduite dans les capitaineries du Pernambuco et de Bahia. Le système colonial n'a pas encouragé leur croissance ou la création des territoires du vin, bien qu'il existe des indications qui ont eu lieu dans les vergers, même d'importance local, tels que décrits Gabriel Soares de Sousa «....il n'y a pas en Bahia tant vin comment il y a dans l'île de Madère et comment produit la capitainerie de São Vicente ... qui récolte déjà trois ou quatre barils de vin chaque année...(1587, p. 166) » [1].

La viticulture a existé dans quelques lieu pour la consommation locale et par/pour l'église, basée sur des cépages Vitis vinifera L., qui cultivait dans les potagers et les vergers domestiques, sous la forme de latada. Les vignobles plus étendus existaient dans les provinces de São Paulo, du Pernambuco, du Minas Gerais, du Paraná, du Santa Catarina [2].

Dans l'ouest du Rio Grande do Sul les jésuites ont introduit des Vitis vinifera dans les régions espagnoles des Missions, aux XVIIe et XVIIIe siècles. À l'est, en 1732, les Açoriens introduisent des cépages portugais aux environs de Rio Grande et de Pelotas et, en 1773, à Viamão et Porto Alegre. À partir de 1824, les immigrants

a e-mail : ifalcade@ucs.br allemands cultivèrent de la vigne dans la région des vallées des rivières Sinos, Caí et Taquari. Pour Inglês de Sousa jusqu'à la moitié du XIXe siècle «[...] les vignobles « gaúchos » étaient tous des cépages Vitis vinifera L., d'abord espagnoles, puis portugaises, françaises ; italiennes et allemandes plus tard $»(1996$, p. 49). Entre 1839 et 1842, a été introduit le cépage Isabel qui s'est rapidement diffusée et aussi bien d'outres cépages de Vitis labrusca (américaines) et hybrides, plus résistantes et adaptées aux conditions environnementales, favorisant l'expansion de la vitiviniculture dans certaines régions [2] [3].

L'organisation des régions où la vigne et le vin ont formé la dynamique économique est liée aux projets de colonisation du XIXe siècle, en particulier les Italiens à partir de 1875, y compris la région Encosta Superior do Nordeste du Rio Grande do Sul, connu par Serra Gaúcha, dans la région de l'escarpement du plateau [4,5], et d'autres petits régions au tour de Urussanga et de la Vale do Rio do Peixe, dans l'État de Santa Catarina; dans la région de São Roque et Jundiaí, en São Paulo; la région de Santa Tereza, dans l'Espírito Santo; et la région de Caldas et Andradas, en Minas Gerais (Fig. 1).

\subsection{La region de vigne et du vin Serra Gaúcha}

La recherche sur l'évolution de l'agriculture avec la viticulture dans la commune de Bento Gonçalves [6], au coeur de la région Serra Gaúcha, a démontré qu'il a eu quatre périodes, que l'on peut appliquer à la culture de la 


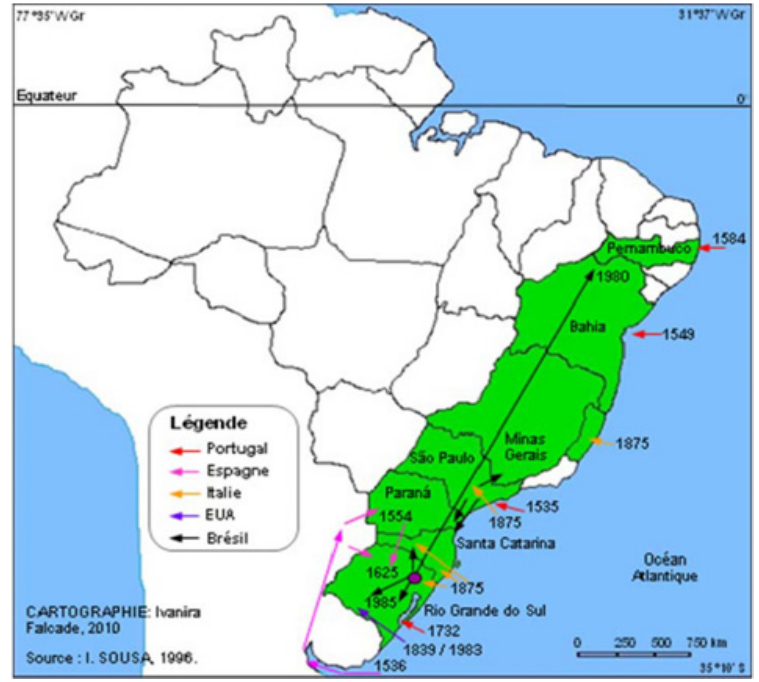

Figure 1. Brésil : dates de références, pays d'origine et états d'introduction et d'expansion de la viticulture, du XVIe au XXe siècle.

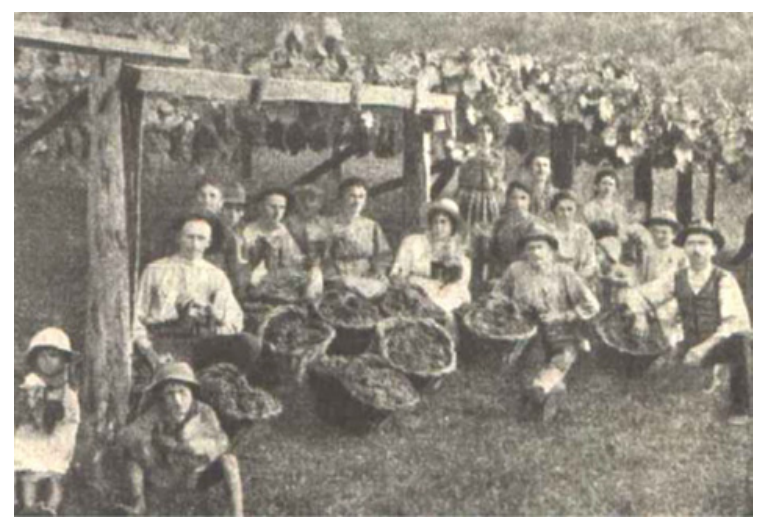

Figure 2. Vendange à Caxias do Sul, dans les années 1920, où s'identifie l'utilisation du système en pergola trentina et des paniers en osier (Photo : Cinquentenário... [4]).

vigne et du vin de la région Serra Gaúcha [7], de même que l'œnotourisme, tel que ci-dessus.

La première période commence en 1875 jusque fin des années 1920, qu'a été la période de la polyculture avec la viticulture (Fig. 2) et la vinification était réalisée dans la cave de la maison, mais ont été aussi fondées certaines caves commerciales, de lesquelles il y a encore peu, par exemple, Cave Salton à Bento Gonçalves et Cave Peterlongo à Garibaldi.

En outre, dans cette période ont été fondées des institutions techniques des recherche et extensions rural, nommées Stations de Viticulture et Enologie, à Caxias do Sul, à Bento Gonçalves, entre d'autres, responsable de la difusion des vignes et améliorations du vin. La production du vin, qui a commencé par la consommation familiale, a généré rapidement un excédent, qui fut commercialisé dans des maisons de commerce dans les communautés, le village ou la ville, dont les propriétaires commercialisaient en centres plus grands.

La deuxième période a été de décennie1930 jusque fin des années 1960 : a été la période du développement de la culture de la vigne commerciale, de la spécialisation du travail et de la centralisation de la production de vin dans de grandes caves localisées dans les villes, comme

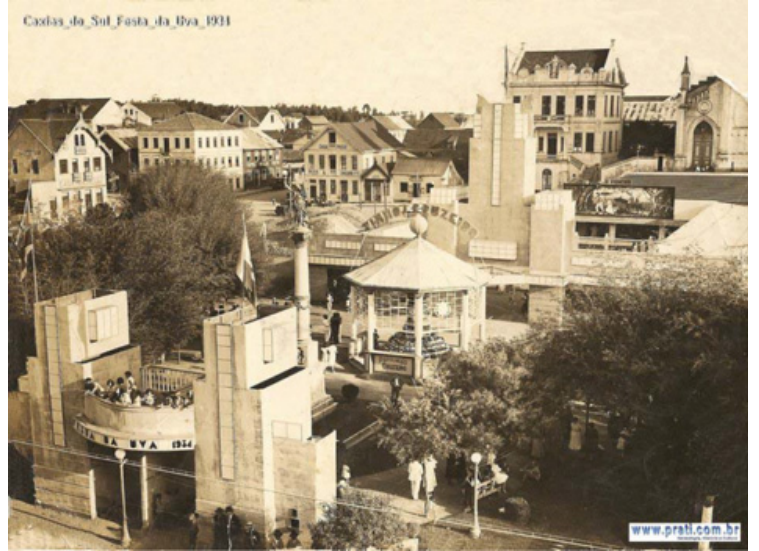

Figure 3. Caxias do Sul : à la Place Dante Aliguieri a été réalisée la Fête du Raisin, en 1934 (Photo : [9]).

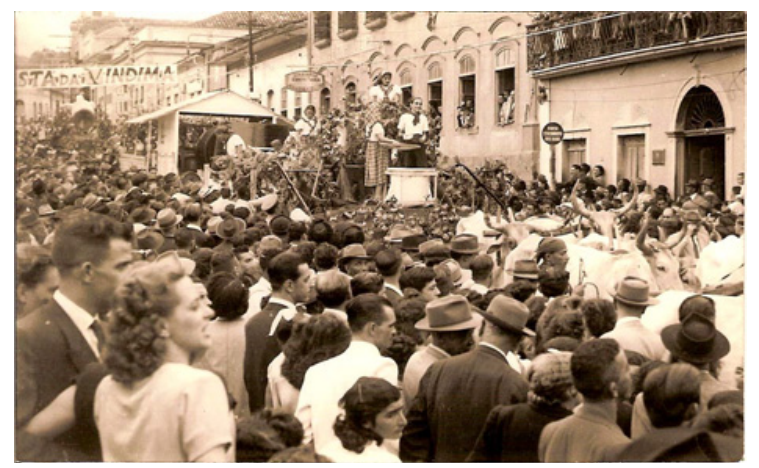

Figure 4. Fête de Vandange réalisée à São Roque (São Paulo), en 1947 (Photo : [10]).

les caves cooperatives Aurora, à Bento Gonçalves ; Garibaldi, à Garibaldi et Aliança, à Flores da Cunha, qu'il y a encore aujourd'hui. Dans cette période a été crée la Fédération des Coopératives de Vin de Rio Grande do Sul (FECOVINHO), l'Union de Brésilienne de Vitiviniculture (UVIBRA) et la première École de Viticulture et Enologie, responsable de la formation spécialisée pendant longtemps.

Dans la deuxième période l'œnotourisme, en général, a été développé à partir des expositions agro-industrielles et de grandes fêtes de raisin et de vin, pour deux ou trois semaines, à Caxias do Sul (Fig. 3) [8,9], à Bento Gonçalves, à Flores da Cunha et puis aussi à Garibaldi, entre outres. Les fêtes ont été réalisées avec plusieurs objectifs, dont l'un était de démontrer que les immigrants avaient surmonté la pauvreté et réalisé des progrès et, comme dit le refrain d'une chanson chantée jusqu'aujourd'hui, « ont créé des communautés et des villes ». Ces fêtes ont été réalisées aussi dans autres régions avec des Italiens, comme en Urussanga, Vale do Rio do Peixe et São Roque et Jundiai (Fig. 4) [10], où la culture de la vigne et du vin toujours est présent.

La troisième période a été des années 1970 jusque la moitié des années 1990 : a été la période de la spécialisation de la viticulture, avec l'expansion des vignobles des Vitis vinifera et l'élaboration des vins fins (au Brésil, dénomination des vins à partir des raisin de Vitis vinifera) avec la qualité beaucoup améllioré ; l'entrée de capitaux multinationaux avec fondation des caves (Moët Chandon, Maison Forrestier, Martini Rossi, 


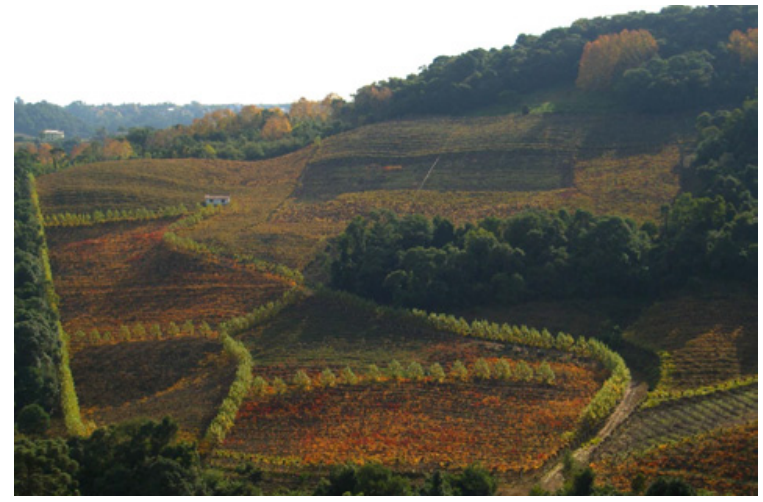

Figure 5. Vignes cultivés dans le traditionnel système latada, soutenue par des tuteurs vivant, les Platanus acerifolia, dans la région Vale dos Vinhedos (Photo : Ivanira Falcade, 2008).

etc.) ; la fermeture de grandes caves brésiliennes traditionnelles (Caves Mônaco, Dreher, Mosele, Luiz Antunes, Riograndense, etc.). La crise dans le secteur a également été l'occasion de la fondation de petites caves dans les secteurs ruraux des quelques municipes, mais surtout à Bento Gonçalves.

Beaucoup d'élèves de l'École de Viticulture et d'Enologie étaient fils d'agriculteurs et, à la fin des études, retournèrent dans leurs familles et commencèrent à opérer des changements dans la viticulture familiale. La culture de cépages communs (Fig. 5) a développé la production des vins de table et de jus de raisin ; puis à partir des années 1990, la culture de cépages viniferas a augmenté pour la production des vins de qualité, non plus seulement présents aux festivals, mais aussi à des concours internationaux.

Très important à cette époque a été la creation de l'Embrapa, institution liée au Ministère de l'Agriculture que, dans le centre de Bento Gonçalves, se dédie à la recherche sur la vigne et le vin. De même, a été crée des institutions sectorielles, comme l'Association Gaúcha de Viticulteurs (AGAVI) et l'Association National d'Enologie (ABE). Dans cette période commencent à être réalisés des événements scientifiques et techniques, tel que l'Évaluation National de Vins, à partir de 1993, organisée pour l'ABE et l'Embrapa Uva e Vinho.

L'œnotourisme à partir d'expositions agro-industrielles ait maintenu ; mais est aussi la période que certaines caves commencent à recevoir des touristes pour un tour dans la cave avec des guides spécialisés pour les conduire, qui se finit par une dégustation de vins avec un passage par la boutique de vente. Les touristes sont importants pour le commerce direct, aussi bien à l'effet pour développer une culture du vin, de son imaginaire, de son identité, de sa consommation à l'échelle nationale. Ceci a impliqué d'autres secteurs dans les caves, dont la communication institutionnelle pour les promotions pour attirer les visiteurs et pour promouvoir leurs produits.

La quatrième période a commencé environ la moitié des années 1990 jusqu'à aujourd'hui (2016) : c'est la période de l'amélioration technique de la vitiviniculture et de la fondation de beaucoup de petites caves qui s'installent en zones rurales et qu'élaborent vins fins; aussi bien la période de la référence géographique des vins de qualité, qui a ancré le vin, explicitement, dans l'espace et dans le paysage avec l'adoption des indications géographiques (Figs. 6 et 7).

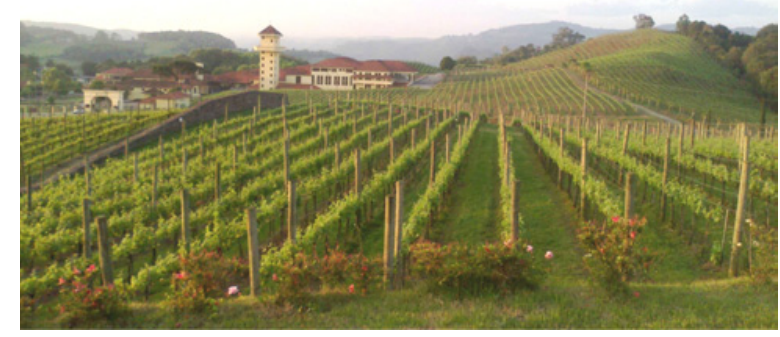

Figure 6. Vignes et cave dans la Appellation d'Origine Vale dos Vinhedos (Photo : Ivanira Falcade, 2012).

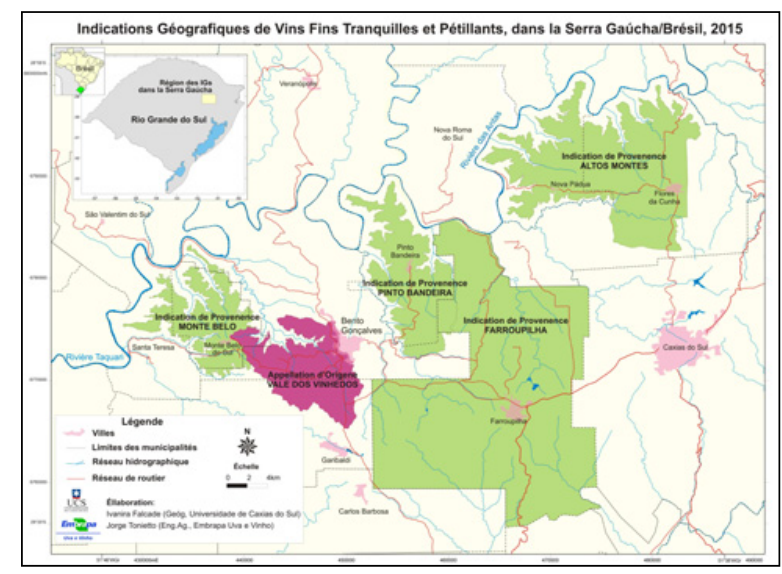

Figure 7. Régions des indications géographiques des vins fins dans la Serra Gaúcha.

Les petites caves s'ont organisé en associations et, entre 1995 e 2005, ont été crées les Associations de Producteurs de vin des régions Vale dos Vinhedos, Pinto Bandeira, Altos Montes, Farroupilha et Monte Belo, avec l'objectif de structurer des indications géographiques, l'œnotourisme, entre d'autres. La collaboration et le soutien des institutions de recherche a été essentiel pour struturer la base technique et pour l'enregistrement de ces régions par l'Institut National de la Propriété Industrielle.

Dans cette période l'œnotourisme était fort inducteur d'autres activités économiques dans la région Serra Gaúcha et, particulièrement, dans la région Vale dos Vinhedos. L'œnotourisme s'est diversifie beaucoup et a acquise une complexité très élevée.

Les projets de grandes fêtes organisés pour la filière sont maintenus, bien aussi les tours dans des caves dans les villes et des événements scientifiques et techniques ; mais surtout sont créés d'autres possibilités, comme des cours de dégustation dans des caves, programmes pour les consommateurs faire la vendange et élaborer son vin ; l'organisation des routes œnotouristiques dans les zones ruraux ; diverses installations d'hébergement (Fig. 8) ; il y a quelques caves qu'ont créés des restaurants et réalisent des évènements sociaux, comme fêtes de mariage ; l'organisation d'un calendrier incluent des évènements sportifs et des arts, entre d'autres.

L'œnotourisme dans la région Vale dos Vinhedos a croisé vraiment beaucoup depuis les années 1990 à les années 2010, d'un peut plus de 1000 jusqu'environ 350.000 touristes (2015), beaucoup d'entre eux ont visité la région à plusieurs occasions, comme a montré l'enquête réalisée en 2010. La recherche a mis en évidence 


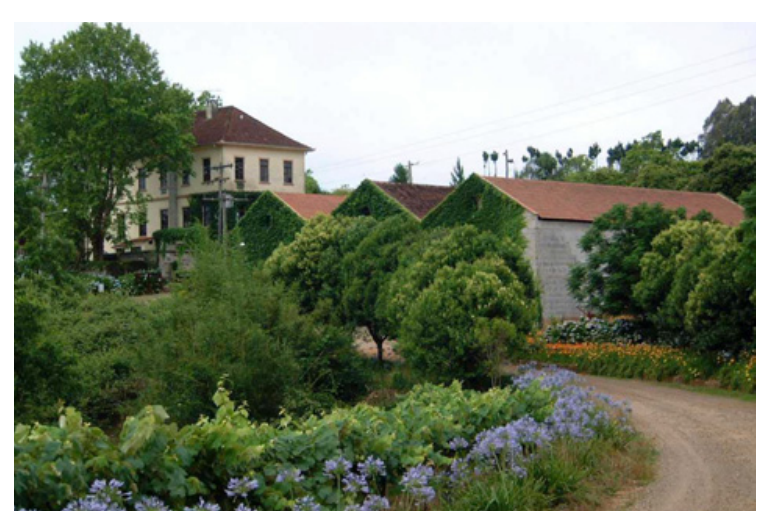

Figure 8. Cave Don Giovani et son hôtel, à Pinto Bandeira (Photo : Ivanira Falcade, 2005).

également que les paysages viticoles et le vin sont les raisons principales pour les touristes visiter la région, en étant que l'image de paysage est le principal image associée au vin des régions (Graphique 1). Ainsi, l'image du paysage viticole peut être utilisé pour créer ou consolider l'image spatiale / territoriale d'un vin [7].

Graphique 1 - Enotourisme dans les régions des Indications de Provenance Vale dos Vinhedos (IPVV), Pinto Bandeira (IPPB) et Monte Belo (IPMB) : image associée au vin (\%) par les touristes, 2010.

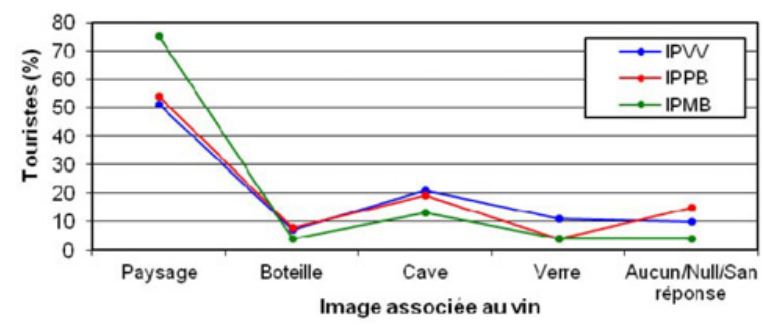

Source : Ivanira Falcade, 2010.

Les actions des associations de la filiere ont influencé, dans cette période, pour le changement et l'adecuation du systeme de normes concerné à la filière liées à la vigne, le vin et le territoire. Dans les années 1980 et 1990, des changements importants sont réalisés dans le cadre juridique brésilien relative à la production, au stockage et à la commercialisation des vins ; en outre on a défini des normes pour l'élaboration de vins dans les caves rurales familiales et les zones vitivinicoles. Le Brésil a participé de la création du Mercosul, de l'OMC et a été admis dans l'OIV, dont les normes sur les indications géographiques ont influencé ce thème dans le pays.

En 2002, dans le cadre de la Fédération des Industries du Rio Grande do Sul (FIERGS), un groupe de six caves a organisé un projet pour l'exportation appelé Wine from Brazil et en 2006, le Ministère de l'Agriculture a fixé, selon la Loi du Vin, trois zones de production de raisin pour les vins fins, très important pour l'exportation des vins : Zone de Production Vitivinicole Serra Gaúcha, Zone de Production Vitivinicole Fronteira, dans l'État de Rio Grande do Sul; et Zone de Production Vitivinicole de la Vale do São Francisco, dans les États de Bahia et Pernambuco. En 2010, le projet avait 34 caves, la majeure partie d'entre elles situées dans la région Serra Gaúcha. Elles avaient participé à diverses foires et expositions, et ont augmenté leurs participations de $15 \%$ à $58 \%$ dans les exportations de vins.

Dans la politique institutionnelle de la filière et de l'État du Rio Grande do Sul a été créé, en 1988, l'Institut Brésilien du Vin (Ibravin) et, en 2001, le Laboratoire de Référence Enologique, le deux très important pour l'évolution de la région et de l'État, bien aussi que du Brésil vitivinicole.

L'organisation de l'espace est un processus [11], donc les dates établies pour le début et la fin des périodes servent de référence, parce que les changements ne se produisent pas avec la même intensité dans tous les lieux, donc il y a des vignerons, des caves et régions vinicoles dans la Serra Gaucha qui sont dans des périodes différentes, de même, quelques-unes encore dans la deuxième ou dans la troisième période.

On note que Tonietto et Mello [12] ont défini une périodisation centrée sur les vins produits, analogue à celle présentée ici. Les auteurs ont nommé de première génération les vins produits de raisins des cépages américains dans la phase de mise en place de la viticulture. La deuxième génération a été la phase d'expansion de la viticulture avec les vins produits de raisins des cépages hybrides et des vinifères. La troisième génération a été la phase de l'expansion de vignobles de cépages européens et d'amélioration de la qualité avec les vins variétales. La quatrième génération est la phase d'affirmation de l'identité régionale, avec les vins de qualités et les indications géographiques.

$\mathrm{Au} \mathrm{XXe}$ siècle, la plupart des régions initiales de culture de vigne et du vin ont connu un changement territorial significatif et la dynamique économique actuelle, en général, a d'autres bases, cependant, la viticulture continue et les éléments de la viticulture restent dans la culture et l'identité régionale [7].

\section{La géographie vitivinicole actuelle}

Au cours des dernières décennies, la viticulture brésilienne a été élargie des traditionnelles régions viticoles pour autres régions liée, surtout, à la question foncière et à la diversification des investissements, telles que la Campanha Gaúcha et la Serra do Sudeste dans l'État du Rio Grande do Sul ; et le Planalto Catarinense dans l'État de Santa Catarina et, de même, dans la région de Vale do Rio São Francisco où si a structuré une région du vin tropical environ de Petrolina-Juazeiro. Dans toutes ces régions sont cultivées essentiellement avec des vignes Vitis vinifera pour l'élaboration du vin fin $[13,14]$.

L'expansion de la viticulture a également eu lieu dans d'autres régions du Rio Grande do Sul et bien aussi pour d'autres régions dans d'autres États, comme São Paulo, Paraná et Minas Gerais (Tableau 1 et Figs. 9 et 10). Dans tous les États sont cultivés cépages de diverses espèces (labrusca, burquina, silvestri, etc.) et hybrides, tant pour l'élaboration de vins, qui sont commercialisés principalement dans le marché national, comme aussi pour la consommation in natura. Entre les régions productrices des raisins de table mérite mention particulière la culture réalisée dans les périmètres irrigués dans le secteur submoyenne de la vallée São Francisco, dans les municipes de Petrolina, Lagoa Grande, Juazeiro, Casa Nova, entre d'autres. La majorité de cette production est destinée au marché international. 
Tableau 1. Viticulture au Brésil : municipaux producteurs ( ${ }^{\circ}$ ), surface cultivée (ha, \%) et production (tonnes, \%), 2014.

\begin{tabular}{l|c|c|c|c|c|r}
\hline États & $\begin{array}{c}\text { Municipaux } \\
\text { Producteurs } \\
\text { sur le Total }\left(\mathrm{N}^{\circ}\right)\end{array}$ & $\begin{array}{c}\text { Municipaux } \\
\text { Producteurs } \\
\text { sur le Total }(\%)\end{array}$ & $\begin{array}{c}\text { Surface } \\
\text { Plantée } \\
\text { (ha) }\end{array}$ & $\begin{array}{c}\% \\
\text { Rroduction } \\
\text { (tonnes) }\end{array}$ & $\%$ \\
\hline Rio Grande do Sul & $451 / 494$ & 91 & 49.995 & 63 & 812.517 & 56 \\
\hline São Paulo & $103 / 631$ & 16 & 8.040 & 10 & 153.822 & 11 \\
\hline Pernambuco & $10 / 183$ & 6 & 6.797 & 9 & 236.719 & 16 \\
\hline Santa Catarina & $192 / 292$ & 66 & 4.897 & 6 & 68.743 & 5 \\
\hline Paraná & $248 / 399$ & 62 & 4.681 & 6 & 78.979 & 5 \\
\hline Bahia & $12 / 416$ & 3 & 2.862 & 4 & 77.504 & 5 \\
\hline Minas Gerais & $130 / 849$ & 15 & 784 & 1 & 11.557 & 1 \\
\hline D'autres 9 États + DF & $69 / 1304$ & 5 & 697 & 1 & 14.048 & 1 \\
\hline Total & $1215 / 4568$ & - & 78.753 & 100 & 1.453 .889 & 100 \\
\hline
\end{tabular}

Source : IBGE, 2016 [15]. Élaboration : Ivanira Falcade.

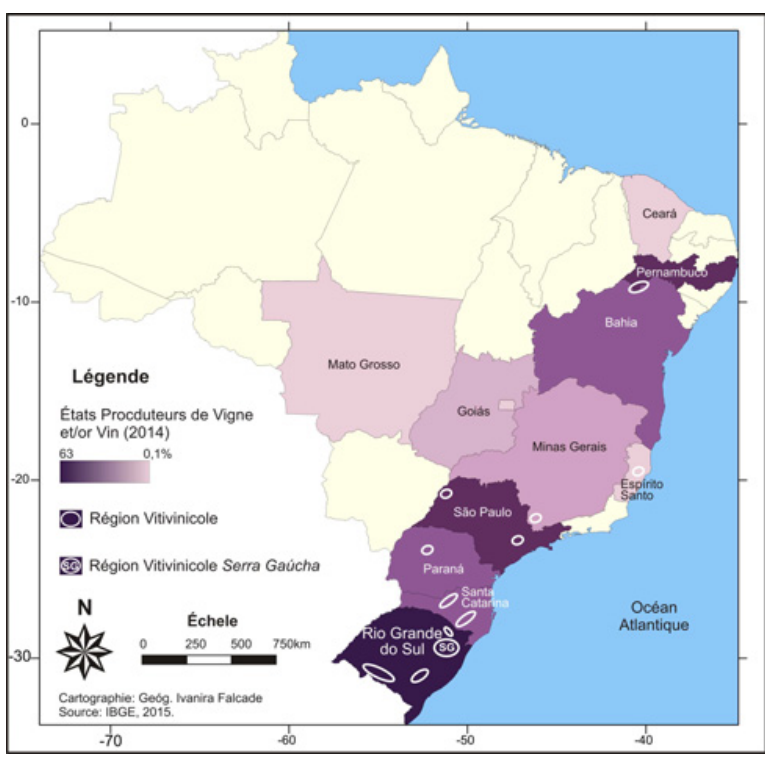

Figure 9. Brésil : les états et les principales régions productrices des vignes et vins, 2014.

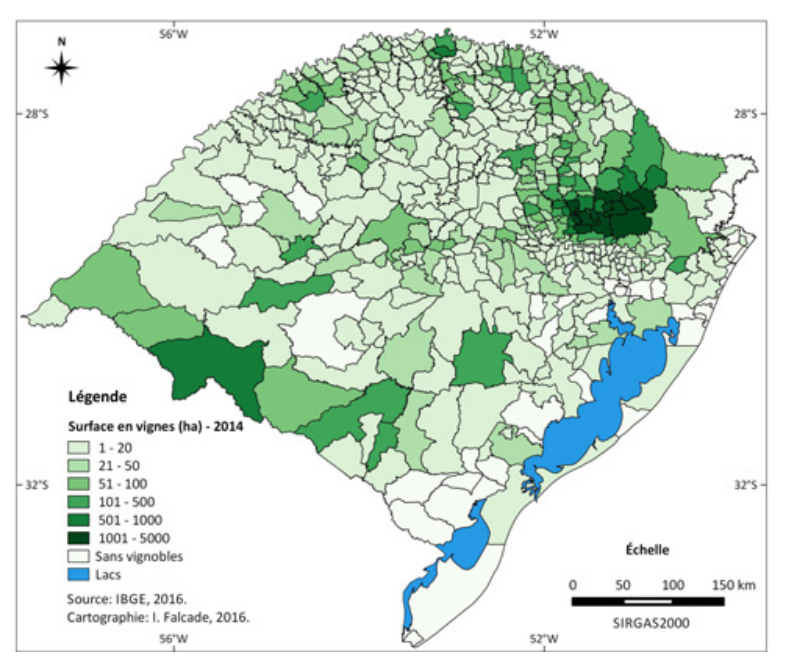

Figure 10. Rio Grande do Sul : la vigne est cultivée dans $91 \%$ des municipaux, on peut dire que ceci est un indicateur d'une identité viticole pour l'État.

Les donnés dans le tableau et les figures montrent que la culture des vignes aujourd'hui existent dans divers Étas du Brésil, mais très concentrée dans quelques municipaux, tandis que dans les trois États du sud (Paraná, Santa
Catarina et Rio Grande do Sul) la viticulture est présente dans beaucoup de municipaux, notamment au Rio Grande do Sul, présente en $91 \%$. Pour ça on peut dire que l'État du Rio Grande do Sul a une identite cultural liée au monde de la vigne et du vin.

D'accord les données d'Ibravin pour l'État du Rio Grande do Sul, en 2014, la majorité des raisins et vins produits ont été de cépages américaines et hybrides en étant $11 \%$ de raisins pour l'élaboration de vin et de produits dérivés ont été de cépages Vitis vinifera, qu'ont produit $10 \%$ des vins élaboré dans l'État [16], en incluant les vins produit dans les régions des indications géographiques dans la Serra Gaúcha (Fig. 7).

\section{Culture et patrimoine du vin}

La culture de la vigne et du vin a construit une marque, pour les sujets et pour la société des régions, dont le paysage viticole distingue et identifie les territoires. En outre, c'est sur quoi centaines de milliers de personnes ont construit sa vie.

L'expression culturelle de la vitiviniculture est présente toujours dans de nombreux éléments matériels et immatériels.

Dans les aspects tangibles des vignobles, on note comme les vignerons utilisent des Platanus acerifolia (les tuteurs vivant) autour des vignobles pour les soutenir, principalement à Monte Belo do Sul, Bento Gonçalves et Garibaldi, maintenant une connexion avec les Étrusques de plus de 2500 ans, qui a créé un paysage tout à fait unique dans le monde du vin (Fig. 5). Il a créé une identité particulièrement différente dans le Brésil, y compris d'autres régions avec l'utilisation de tuteurs vivants (Asprinio de Aversa, Vinhos Verdes et Los Cintis).

Il y a beaucoup de vignes que ont été modifiés, y compris le système de conduite, mais il y a des vignerons qui maintiennent l'utilisation du platane, élément emblématique de régions d'Indication de Provenance Monte Belo et Appellation d'Origine Vale dos Vinhedos, même que le système de conduite a été modifié de latada pour espalier (Fig. 11). Les transformations dans la viticulture montrent aussi que certains vignobles traditionnels ont été éliminés et les terrains ne sont pas plus utilisés. Les platanes qui ont soutenu de vignobles n'ont pas été taillés et ils grandissent librement. Ces platanes et le secteur aux alentours forment sites archéologiques qui 


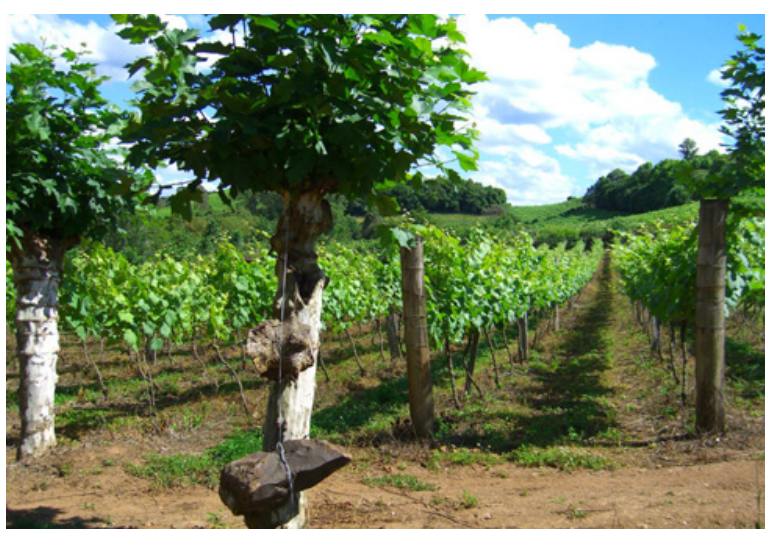

Figure 11. À Monte Belo vignes en espalier soutenues par le Platanus acerifolia (Photo: Ivanira Falcade, 2012).

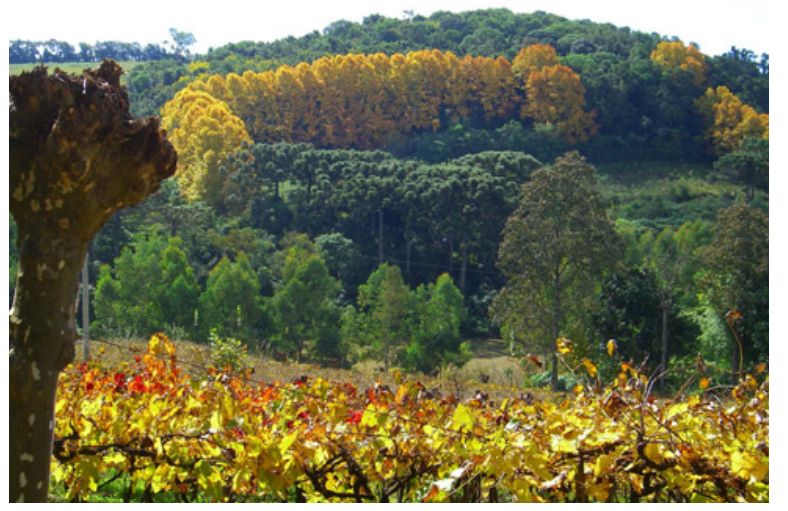

Figure 12. Région Monte Belo : le platanes que soutient un vignoble traditionnel, le pin brésilien et le site archéologique (Photo : Ivanira Falcade, 2012).

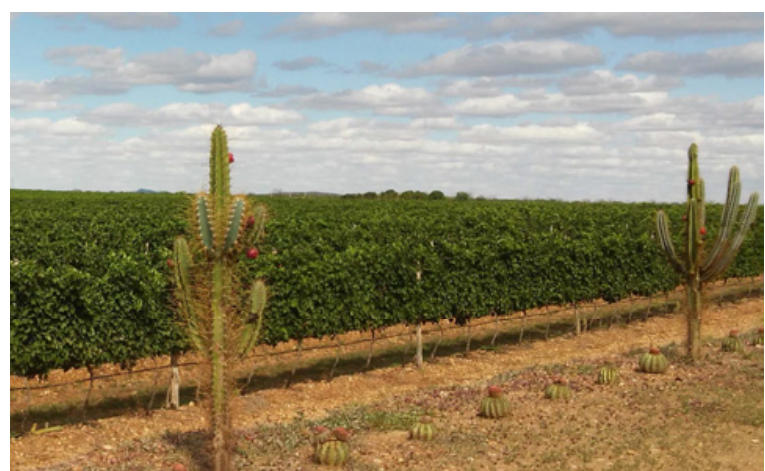

Figure 13. Vignes et cactées dans la région semi-aride de la Vale do Rio São Francisco, à Petrolina-Juazeiro et aux alentours (Photo : Ivanira Falcade, 2014).

témoignent le système viticole et le travail matérialisé dans l'espace (Fig. 12).

Dans les régions de vignes et du vin sur le plateau au sud du Brésil on trouve le pin brésilien (Araucária angustifolia). Cette espèce est l'élément emblématique naturel plus importante dans les régions des vignes Serra Gaúcha, Campos de Cima da Serra et Planalto Catarinense (Fig. 12). En outre, dans la région tropical semi-aride, à côté des vignobles, on trouve des espèces du biome caatinga, comme les cactées (Fig. 13). Ces éléments sont importants pour caractériser les régions et pour les situer et identifier dans le monde du vin.
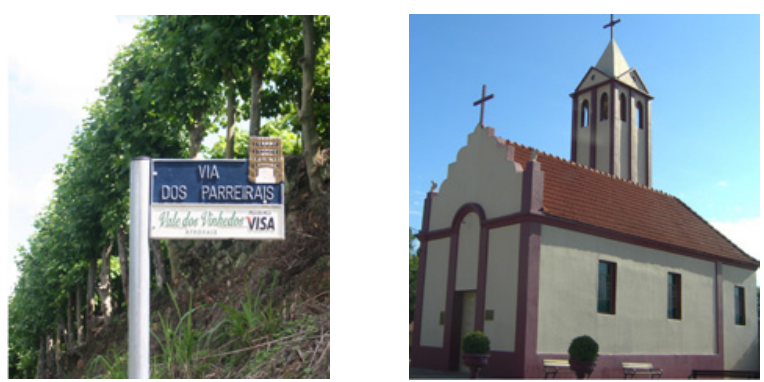

Figures 13 (à gauche) et 14 (à droite). Représentations symboliques immatériels/matériel liées à la culture.

Il y a beaucoup d'autres éléments matériels dans la région vitivinicole Sera Gaúcha, comme la formation de murs à roche pour soutenir le sol dans une forte pente ou pour former des terrasses. Il y a aussi des murs et des piliers en pierre que soutiennent quelques vignobles traditionnels qui ont été plantés dans les premières périodes de la viticulture. Un autre aspect de la culture est l'usage des osiers pour attacher les branches des vignes que peuvent être trouvés tant dans la viticulture traditionnel comme en quelques vignobles modernes.

Les outils et les machines, les barriques et bouteilles, les bâtiments des caves, avec des éléments constructifs, entre d'autres aspects, révèlent la créativité et la connaissance des vignerons et des industriels du vin pour solutionner leurs difficultés et problèmes. Ces gens sont parties et constructeurs des territoires du vin, avec les routes, villes, indications géographiques, etc..

Parmi les aspects intangibles, il y a les traditions des différentes formes de la consommation de vin, les fêtes, les toponymes, la littérature, la musique, les représentations symboliques et iconographiques, y compris religieuses (Fig. 14).

Le monde de la vitiviniculture a défini quelques toponymes au Brésil [17,18], puisque des nomes comme Commune « Vale dos Vinhedos » et Micro-region «Vitivinicultora de Caxias do Sul»; les nomes des diverses municipaux comme Videira et Vinhedo ; le nome de la plus grande région de œnotourisme dans le Rio Grande do Sul «Raisin et Vin »; ou le nom d'une route, la Route des Vignobles (Fig. 13). Entre les représentations symboliques et iconographiques, mérites mention particulière le monument en forme d'un grand tonneaux qui se trouve à l'entrée sud de la ville de Bento Gonçalves, l'Église de Saint Benoit aussi en forme d'un grand tonneaux or l'Église de Notre Dame de Niege où ont utilisé de vin par sa construction (Fig. 14) ; en plus les vitrages des églises ou les tuiles du trottoir au centreville de Bento Gonçalves avec des dessins de vrilles et de grappes de raisin, entre d'autres éléments.

Les éléments et les complexes culturelles des régions viticoles sont un héritage diversifié et dynamique. On note qu'il y avait une évolution dans la perception de l'importance de ce patrimoine culturel dans le Brésil: il y a de caves qui ont créée petits musées pour la préservation et la valorisation des vignes et des vins, des machines et des outils, des bâtiments, des photographies.

En outre, la filière vitivinicole et le gouvernement, en partenariat, ont délimité et enregistré des indications géographiques (Vale dos Vinhedos, Pinto Bandeira, Altos Montes, Monte Belo et Farroupilha) ; bien aussi ont défini 


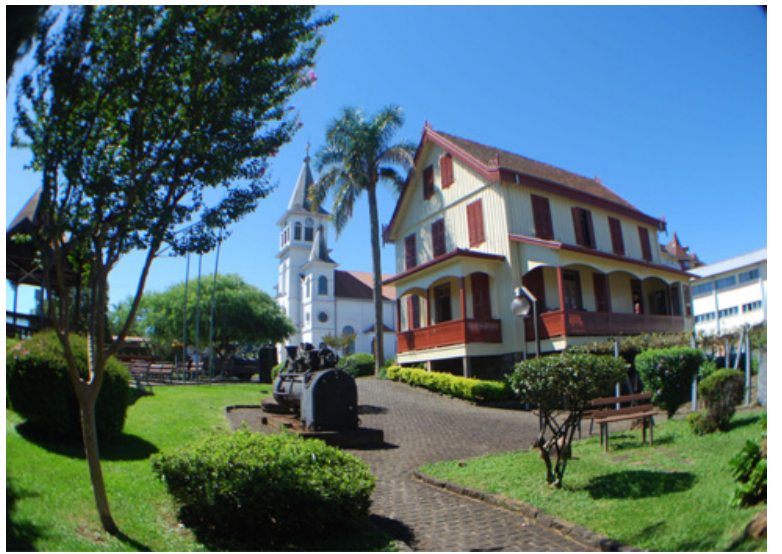

Figure 15. Musée du Vin dans la ville de Videira, Santa Catarina (Photo : [19]).

la Vale dos Vinhedos comme patrimoine historique et culturel du Rio Grande do Sul et ont créés le Jour du Vin du Rio Grande do Sul. En outre, il met en évidence la culture de la vigne et du vin dans les musées ou les archives historiques, en plus dans l'État du Rio Grande do Sul et dans l'État de Santa Catarina (Fig. 15) [19], qui contribue pour la valorisation et à la préservation du patrimoine culturel et territorial du vin.

\section{Conclusions}

La mise en place des régions et des territoires de vignes et du vin est plus récente au Brésil que dans d'autres pays, mais pour les personnes concernées est de la plus haute importance. L'évolution a montré que les limites de la viticulture sont relative et l'actuelle géographie de cette culture occupe des espaces en latitudes beaucoup varié, avec la possibilité de s'étendre et de se développer encore plus.

La valorisation et patrimonialisation de la culture du vin dans des actions collectives concrètes dépendra de l'importance qui les acteurs impliqués leur donnent la filière productive, les institutions d'enseignement et de recherche, les gouvernements, les organisations de la société civile, entre autres.

Le Loi du Paysage Culturel Brésilienne, et d'autres règles du cadre juridique, peut soutenir des actions sur les paysages culturels en permanent évolutions, vers le sens de la Convention de l'UNESCO pour les paysages culturels de type II, deuxième catégorie, en particulier pour constituir le cadre sur lequel on peut patrimonialiser (mais pas cristalliser) le Paysage Viticole de la Serra Gaúcha comme patrimoine du Brésil.

\section{Références}

[1] G. S. de Sousa. Tratado descritivo do Brasil. (1587). Disponible sur: www.dominiopublico.gov.br/ download/texto/me003015.pdf

[2] S. I. de Sousa. Uvas para o Brasil. São Paulo: ESALQ (1996)
[3] R. Dal Pizzol, L. V. E. Pastor. Paisagem do vinhedo rio-grandense. Bento Gonçalves: R.C.Dal Pizzol (2016)

[4] Cinquentenario della Colonizzazione Italiana nell Rio Grande del Sud 1875-1925, Roma/Porto Alegre: Ministero Degli Affari Esteri/Livraria do Globo (1925)

[5] E. Pellanda. Aspectos gerais da colonização italiana no Rio Grande do Sul. In: Álbum comemorativo do $75^{\circ}$ aniversário da colonização italiana no Rio Grande do Sul, Porto Alegre, Globo, p.33-64 (1950)

[6] I. Falcade. A organização do espaço agrário em Bento Gonçalves. In: Anais do IV ENGA, 1984. Santa Maria: EDUFSM, v.2, p.207-210 (1984)

[7] I. Falcade. Le paysage comme représentation spatiale: le paysage viticole comme symbole des indications géografiques des régions Vale dos Vinhedos, Pinto Bandeira et Monte Belo (Brésil). Thèse de doctorat. Porto Alegre/Dijon: UFRGS / UB (2011)

[8] C. M. P. J. Ribeiro. Festa e identidade : como se fez a festa da uva. Caxias do Sul: EDUCS (2002)

[9] Photo disponible en : www.prati.com.br.

[10] Photo disponible en : http://andiamomem oriaitalianaemsr.blogspot.com.br/2012/01/ os-italianos-e-vitivinicultura-em-sao. html

[11] I. Falcade. As indicações geográficas (IG's) e a reorganização do espaço rural brasileiro. In: G. J. Marafon, J. Rua, M. A. Ribeiro. Abordagens teórico-metodológicas da geografia agrária. Rio de Janeiro : EDUERJ, p. 225-253 (2007)

[12] J. Tonietto, L. M. R. Mello. La quatrième période évolutive de la vitiviniculture brésilienne: changements dans le marché consommateur du pays. In: 26th Congress OIV, Adelaide, 2001. Congress Proceedings. v.3, Adelaide: OIV, p. 272-280 (2001)

[13] J. Tonietto, I. Falcade. Regiões vitivinícolas brasileiras. In: G. Kuhn. Uva para processamento produção. v.34. Brasília: Embrapa, p. 10-14 (2003)

[14] I. Falcade, J. Tonietto. Caracterização geográfica das regiões de vitivinicultura no Brasil. In: Congresso Brasileiro de Viticultura e Enologia, 7, 1993, Bento Gonçalves. Anais... Bento Gonçalves: Embrapa Uva e vinho, p. 42-53 (1993)

[15] IBGE. Produção das lavouras permanentes. Disponible sur: http://www.sidra.ibge.gov . $\mathrm{br} / \mathrm{bda} / \mathrm{tabela} /$ istabl. asp? $\mathrm{c}=1613 \& \mathrm{z}=\mathrm{t} \& \mathrm{o}=11$.

[16] IBRAVIN. Disponible sur : http://www.ibravin. org.br/admin/arquivos/estatisticas/ 1473079559.pdf

[17] I. Falcade; J. Tonietto. A viticultura para vinhos finos e espumantes da Região da Serra Gaúcha: topônimos e distribuição geográfica. Bento Gonçalves: EMBRAPA-CNPUV (1995)

[18] Disponible sur: http://www .ibge.gov.br

[19] Disponible sur: http://www . valesdauvagoethe. com.br/ipvug. php?id=1 